\title{
Specific Organ Targeted Vestibular Physiotherapy: The Pivot in the Contemporary Management of Vertigo and Imbalance
}

\author{
Anirban Biswas ${ }^{1} \cdot$ Bibhas Barui $^{1}$
}

Published online: 20 November 2017

(C) Association of Otolaryngologists of India 2017

\begin{abstract}
Introduction Advancements in our understanding of vestibular physiology and how it is changes in different diseases have established that of the three therapeutic approaches to treat disorders of the vestibular system viz. pharmacotherapy, surgery and physical therapy, it is the later i.e., physical therapy which is the most efficacious modality in the management of balance disorders. The futility of vestibular sedatives in the correction of vestibular disorders and in the restoration of balance and the very limited role of surgery has now been recognised. Advancements in vestibulometry now enable us to localise any lesion in the vestibular system with utmost precision and also determine the exact cause of the balance disorder. The site of lesion and the specific organ that is defective can now be very precisely identified. Treatment modalities especially that for physical therapy hence have to be organ specific, and if possible, also disease specific.

Aims and Objectives The study aims at evaluating the efficacy of physiotherapy in the management of balance disorders and also assesses the efficacy of organ targeted physical therapy, a new concept in restoring balance after vestibulometry has identified the offending organ.

Materials and Methods The study was conducted in the specialised physical therapy unit for balance and gait disorder patients which is a part of Vertigo and Deafness Clinic in Kolkata, India. Special instruments for physical therapy devised by the first author were used for stimulation of specific sense organs in the vestibular labyrinth that
\end{abstract}

Anirban Biswas

anirbanbiswas@vsnl.com

1 Vertigo \& Deafness Clinic, BJ-252, Salt Lake, Kolkata, West Bengal 700091, India were found to be defective in vestibulometry. Specially made Virtual reality programs were used in patients suffering from psychogenic balance disorders. The pre and post therapy status was evaluated by different standard scales to assess balance and dizziness.

Results Very promising results were obtained. Organ targeted physiotherapy where defective sense organs were specifically stimulated showed remarkable improvement in different measures. Virtual reality exercises too showed very promising results in patients of psychogenic vertigo.

Keywords Vestibular physiotherapy .

Management of balance disorders .

Physical therapy for vertigo

\section{Introduction}

Physiotherapy or physical therapy is defined as the treatment of disease, deformity and/or disability by physical methods such as massage, heat treatment, and exercise or physical workouts rather than by medicines or by surger$y$. The essence of physiotherapy is to improve and enhance the functionality of a dysfunctional or malfunctioned body part and to stimulate and boost the residual function of a damaged organ and thereby provide a better quality of life. Physical therapy adapts the body to overcome challenges that are limiting daily physical activities necessary for sustenance of normal life. Vestibular physiotherapy is physical therapy that helps in the correction of vestibular disorders (that present as vertigo/imbalance/unsteadiness) and in the improvement of body's balances mechanism. Some ailments respond to medical treatment, some to surgery and some to physical therapy. Vestibular disorders respond best to a two pronged therapeutic approach viz. 
(1) Medical therapy directed to treat the underlying medical disorder that is causing the vertigo/imbalance e.g., steroids for vestibular neuritis, diuretics for Meniere's disease, psychotropic drugs SSRIs/ benzodiazepines for psychogenic vertigo, migraine prophylactic drugs for Vertiginous migraine etc. [1].

(2) Diligent physical therapy that is directed to restoration of the normal balance function after it has been deranged by disease. This again acts in different ways. Some physical therapies just improve the general balance function and sharpen the balancing skills of the subject, some enhance the vestibular compensatory mechanism (elaborated below) and some enhance the functionality of a damaged part of the vestibular labyrinth or that of a deranged mechanism in the vestibular system. [2].

\section{Literature and Review}

\section{The Unique Challenges in Treating Balance Disorders}

Vestibular disorders [3] cause extreme morbidity and induce a severe impact on the quality of life of the patient suffering from it. Disorders of the vestibular system are very incapacitating and cripple the patient not only physically but also mentally. Unfortunately, however, the biological mechanism of maintenance of balance and how different diseases of the balance system modify this normal functioning of the balance system was ill-understood till about a decade back. This is due to the inherent complexity of the mechanism of maintenance of balance which becomes still more complex when afflicted by disease as a huge lot of internal adjustments take place when the balance system starts malfunctioning.

Head spinning or vertigo and imbalance or unsteadiness is only the external manifestation or just the symptom of some internal disease which needs to be diagnosed first for effective treatment. But as the understanding of the pathophysiology was poor in the not so distant past, the diagnosis of the underlying causative disease could not be confirmatively made in most patients till a few years back. Consequently, treatment meted out to these patients was illogical, irrational and empirical and what the medical community was doling out under the guise of treatment of vestibular disorders was actually an utter disservice and mismanagement of these hapless patients.

The common practice of treating balance disorders all these years was hence limited to prescribing anti-vertigo drugs or vestibular sedatives (like betahistine/cinnarizine/ meclizine/prochlorperazine/dimenhydrinate etc.) that merely helped in partly and temporarily reducing the symptom of head spinning without correcting the underlying cause of the disorder in any way [4]. As for patients with the imbalance, the vestibular sedatives did not help at all. Rather, by sedating and reducing the sensitivity of the balance organs/vestibular system they actually aggravated the patient's imbalance. Vestibular sedatives neither corrected the underlying disease causing the balance disorder nor restored the balance function that had been deranged by the disease. As for physiotherapy in the management of balance disorders, the therapy was (and still is) limited to non-specific Cawthrone Cooksey exercises.

The balance organs are special sense organs where dead cells do not regenerate; yet then, after the balance organs have been damaged by disease, most (but not all) patients slowly re-gain their normal or near normal balance function. This happens not because the damaged cells regenerate, but because we have an in-built system called the vestibular compensatory mechanism [5] which brings about some functional changes in the brain by virtue of which a patient having a damaged balance organ at least partly if not wholly gets back normal balance function. This is a unique system of the human body and the best part of it is that it is a completely natural process. Medicines do not enhance this process of vestibular compensation. Rather, most, if not all vestibular sedatives that are used for symptomatic relief in vertigo depress this natural process of restoration of balance that is ingrained in our biological system. But, physical therapy in different forms does enhance and expedite this natural mechanism of vestibular compensation in a very big way. Herein lies the importance of physical therapy in the management of balance disorders.

\section{Contemporary Consensus on Solutions and Strategies for Effective Management of Balance Disorders}

It is only in the last 10 years that a paradigm shift has taken place in the management of vestibular disorders. The current approach in management of balance disorders is to diagnose the underlying disease that is causing the balance disorder and then to localise the exact site of lesion and identify which specific organ or system is at fault. Once this is done, specific drug therapy to treat the underlying disorder and specific physiotherapy to stimulate specifically the damaged organ or the dysfunctional system is instituted. It is now known that most if not all of the vestibular sedatives that are/were used for treating vestibular disorders actually jeopardise the natural process of restoration of balance function and the use of such medicines is now unanimously denounced and long term use is universally abhorred. In fact, some of these drugs 
like betahistine and cinnarizine are not even approved by the FDA of USA which is a regulatory body for use of medical products/devices respected and followed internationally. The current medical consensus is that if at all these anti-vertigo drugs [6] are ever used, then, the use must be restricted to just 3-5 days never ever beyond that. The scope of medical treatment in balance disorders is strictly confined to treating the underlying causative disease after it has been confirmatively diagnosed by a thorough history taking, clinical tests and by the current investigative modalities i.e., modern vestibulometry. The medical treatment is augmented by physical therapy for the best treatment outcome. But for this the physical therapies for improving the balance functions need to be customised for each patient. Each balance disorder patient has different needs which require to be addressed by the team of neurotologist, vestibular physiotherapist and neuro-rehabilitation specialist.

\section{The Unique Role of Physical Therapy in Balance Disorders}

Physical therapy is currently considered the mainstay of treatment in balance disorder patients especially for restoring the normal balance function and bringing back the patient to mainstream. It has been found to be extremely beneficial and effective for the restoration of balance function after the balance organs have been damaged by disease. Advancements in our understanding of the mechanism of balance in normal persons and also when affected by disease have established the supreme efficacy of physical therapy in the management of balance disorders [7]. Physical therapy is beneficial in augmenting the physical stability of any individual; not only balance disorder patients, but also in normal persons who do not have a balance disorder. The balance system has an inherent plasticity by virtue of which the balance faculty can be augmented by physical training i.e., by physiotherapy and decreased by disuse. Acrobats who perform highly skilled balance acts like tight rope walking are all normal persons like any of us whose balance systems have been sensitised and sharpened by intensive physical training only. This training is nothing but physical therapy. Hence, in a person with a compromised balance function due to any disease, the functionality or the capacity of the balance system can definitely be enhanced substantially just by physical therapy. Physiotherapy for balance improvement and augmenting general stability in challenging balance situations is used in fall prevention too and is hence immensely useful in improving quality of life of aged patients. Some special forms of physical therapies like those employing virtual reality systems also help patients overcome the fear of fall by adapting them to different types of challenging situations [8].

In patients with disorders of the vestibular system, physical therapy restores the balance function by three different physiological mechanisms all of which are linked to each other viz

(1) Enhancing and expediting the vestibular compensatory mechanism by exercises like (a) standing and walking on uneven surfaces or soft surfaces so that the proprioceptive input is reduced and the patient learns to manage balance by utilising the vestibular and visual inputs; (b) standing and walking first on hard even surfaces and then on soft uneven surfaces with eyes closed so that the patient learns to maintain balance without visual input and with reduced proprioceptive input;

(2) Improving general balance function by exposing the patient to different types of challenging situations like walking unsupported with eyes closed, trying to balance on one leg, playing easy games like catching a ball standing on a pliable surface like a trampoline, trying to sit and balance on a gym ball etc. Different centres for vestibular physiotherapy can have its own protocols for increasing the balance capability of the patient and depending on the special requirements and physical capabilities of the patient the exercises need to be customised;

(3) Specifically and individually stimulating the defective sensors in the vestibular labyrinth in the ears (like the utricle/saccule/semi-circular canals) to sharpen and augment their sensitivity after the defect has been identified by the modern vestibular function tests e.g., moving the head in the plane of the semicircular canal that has been identified to have been damaged [9, 19].

\section{Materials and Methods}

53 patients diagnosed with different types of vestibular disorders and thoroughly investigated with all requisite vestibular function tests viz, VNG including oculomotor tests, VHIT, ocular and cervical VEMP, Subjective Visual Vertical Test (SVV), Dynamic Visual Acuity (DVA) and Craniocorpography (CCG) were enrolled for the study to assess the role of pure physical therapy in improving the balance disability and physical impairment. The patients were evaluated pre-therapy by Activity Balance Confidence Scale, Burg Balance Scale and the Dizziness Handicap Inventory scale and re-evaluated post therapy on these scales after 10 sessions. The study was carried out in the physiotherapy unit of Vertigo and Deafness Clinic at BJ- 


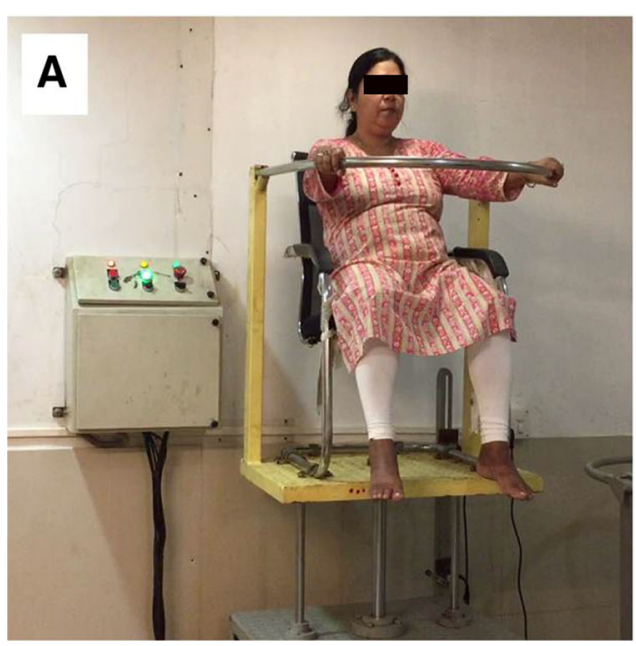

Fig. 1 a, b A set-up for stimulation of the saccule. In this hydraulically operated electromechanical system (a) the patient can be made to move up and down while seated on a chair. This is done first with eyes open and then with eyes closed such that the sensing of the linear movement in the vertical axis is done by the saccule as

252 Salt Lake Kokata, India which is equipped with all modern diagnostic and therapeutic equipment related to balance and hearing disorders owned and run by the authors.

The physical therapies were carried out by some new tools devised by the first author and by some standard available tools most of which were specifically improvised in-house at Vertigo and Deafness Clinic Kolkata. Some of the tools used were:

(1) Hydraulically operated linear vertical movement generator at low frequency stimulation of saccule (Fig. 1a)

(2) Trampoline for generating high frequency linear vertical movement for stimulation of the saccule (Fig. 1b)

(3) Hydraulically operated linear horizontal movement generator for stimulation of utricle at low frequencies (Fig. 2)

(4) Mechanically operated angular head movement generator for anterior and posterior canals (Fig. 4)

(5) Electromechanically operated lateral angular movement generator of lateral semi-circular canals at low frequencies (Fig. 3)

(6) Stability Trainer from Theraband-Blue, Green and Black foams of different grades of firmness/pliability for different grades of gradually varying proprioceptive stimulus (Fig. 5a)

(7) Gym Balls from Theraband for stability improving exercises like lifting one hand and one leg while sitting on the gymball (Fig. 5b) and activities like catching a ball while balancing on the gymball

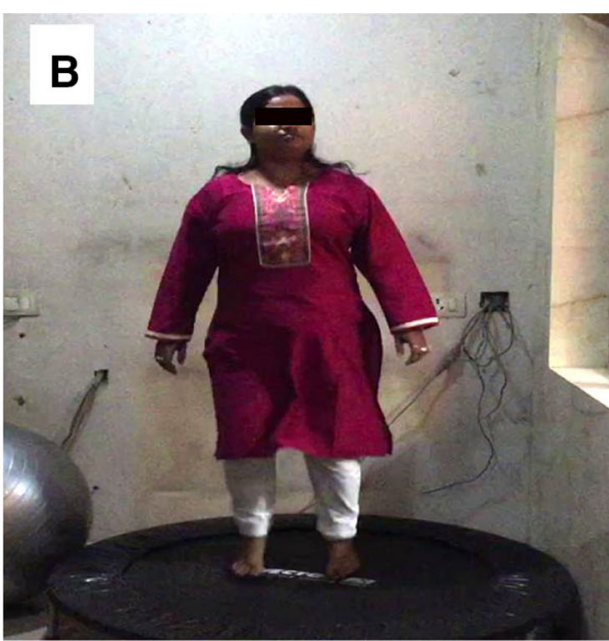

much as possible. The chair stimulates the saccule at a low frequency of stimulation. Once the patient is comfortable with the low frequency stimulation the patient is made to jump on a trampoline (b) for high frequency stimulation of the saccule after being anchored properly by harnesses (not shown here) attached to the walls or to the roof

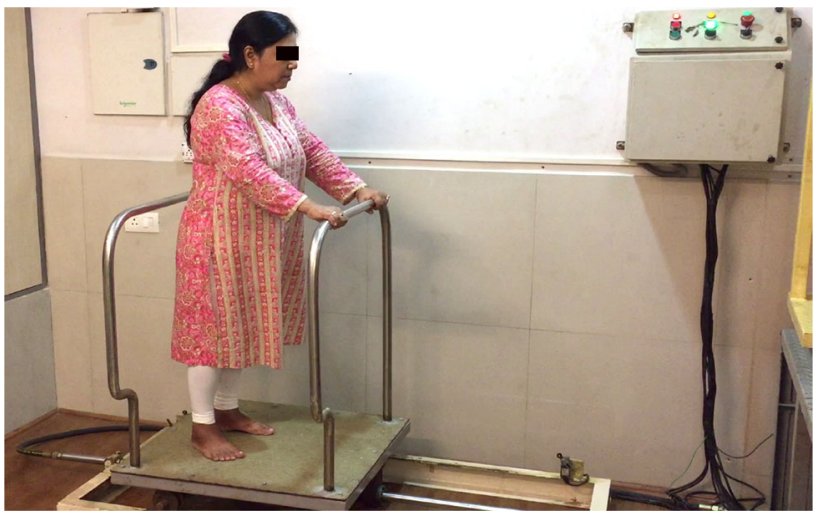

Fig. 2 A hydraulically operated electromechanical device to specifically stimulate the utricle. The platform moves in the linear plane horizontally. The patient stands on the moving platform first with eyes open holding on to the railings and then without holding the railing with eyes open and then with eyes closed. The speed of movement can be slowly increased and the task made more difficult by making the patient stand on a soft surface first on two legs then on one leg

(8) Stability and Balance improving exercises using a Trampoline (Fig. 6a, b), a Bosuball (Fig. 6c) and Foam pads (Fig. 6d)

(9) Body Weight Support unweaning System improvised in the clinic for gait disorder patients and patients with a psychological fear of walking (Fig. 7)

(10) Virtual Reality Software(s) made in-house through NeuroEquilibrium Diagnostic Systems for training in Virtual Reality environment (Fig. 8)

If vestibulometry diagnosed a patient has a defect in the anterior semi-circular canal, of the left side the patient was 


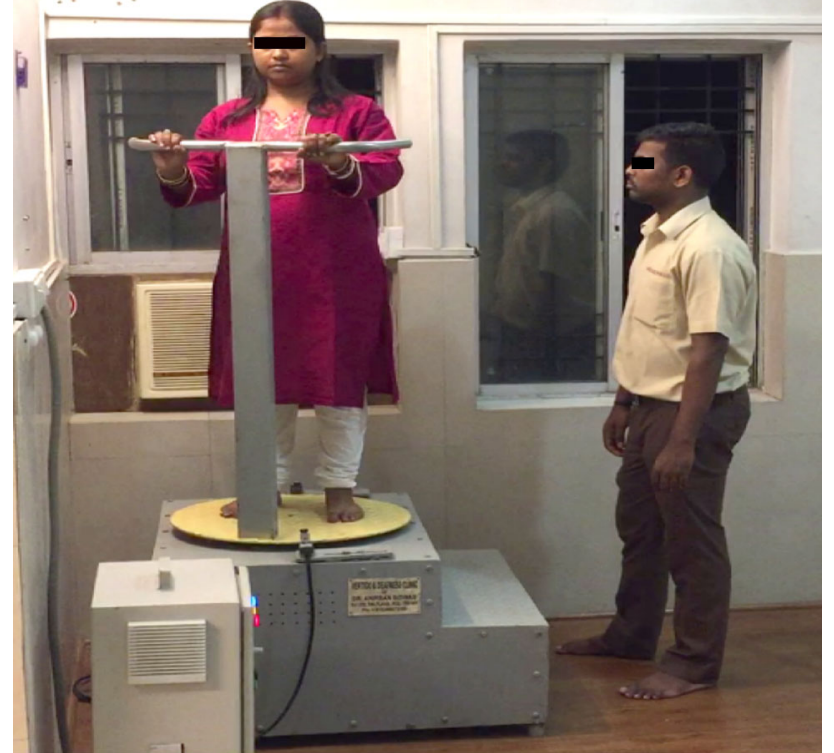

Fig. 3 Set up for precisely stimulating the lateral semi-circular canals only. The electromechanical device rotates the platform in clockwise/ anti-clockwise manner to specifically stimulate the left and the right lateral semi-circular canals. The patient stands on the revolving platform first holding on to the handles then without holding to the handles and then with eyes closed and finally with eyes closed on a foam pad to eliminate visual and proprioceptive inputs

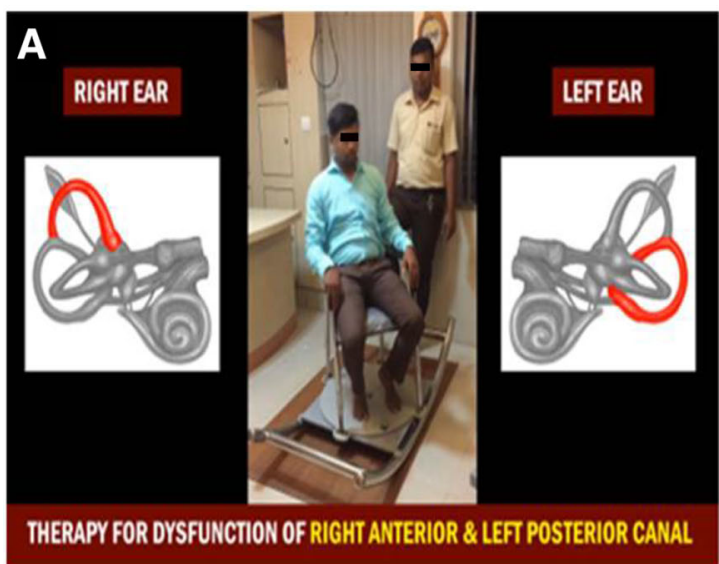

Fig. 4 a, b Targeted physiotherapy for specifically stimulating the anterior (superior) and the posterior semi-circular canals. a Is the position for stimulating the right anterior and left posterior semi- subjected to specific physical therapy that precisely stimulates the anterior semi-circular canal of the left side. If there was a defect in the saccule the patient was subjected to up-down movements in a hydraulic chair and after the patient became comfortable with this low frequency stimulation, then the patient is made to jump on the trampoline after securely anchoring the patient with specially made harnesses for high frequency stimulation of the saccule. If there was a defect in the utricle, then the utricle is stimulated by side to side and front-back movements in a hydraulic platform. There are very special gadgets for stimulating each different sensor in the vestibular system all devised by the first author with the help of engineering fabricators.

Some patients were diagnosed by the first author to have a psychic overlay causing a sense of imbalance and fear of falls but showed more or less normal findings in vestibulometric tests. These patients were made to undertake, some customised virtual reality programs (Fig. 8) to expose the patient to different mentally challenging balance situations so that the sense of insecurity and the apprehension of losing balance or undue fear of falling is overcome. These modalities actually are a form of Cognitive Behavioural Therapy and act by a process of Exposure and Response Prevention and bring back such patients to mainstream.

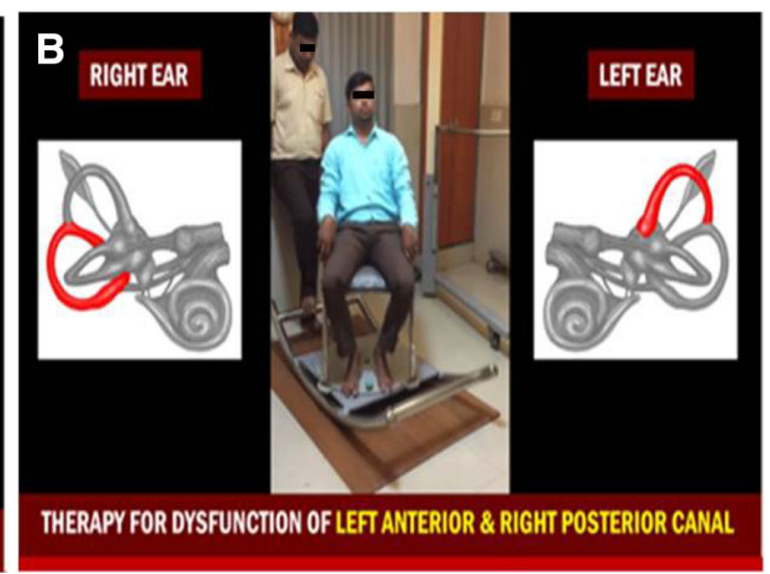

circular canals and $\mathbf{b}$ is the position for stimulating the left anterior and right posterior semi-circular canals 


\section{Results}

\begin{tabular}{|c|c|c|c|c|c|c|c|c|}
\hline Subjects & Vestibulometry & $\begin{array}{l}\text { Physical therapy } \\
\text { intervention }\end{array}$ & $\begin{array}{l}\text { Abc }(\%) \text { pre } \\
\text { treat }\end{array}$ & $\begin{array}{l}\text { Abc }(\%) \text { post } \\
\text { treat }\end{array}$ & $\begin{array}{l}\mathrm{Bbs}\left(\_/ 56\right) \\
\text { pre treat }\end{array}$ & $\begin{array}{l}\operatorname{Bbs}\left(\_/ 56\right) \\
\text { post treat }\end{array}$ & $\begin{array}{l}\text { Dhi pre } \\
\text { treat }\end{array}$ & $\begin{array}{l}\text { Dhi post } \\
\text { treat }\end{array}$ \\
\hline 1 & Ab lateral canal & $\begin{array}{l}\text { Specific organ therapy, } \\
\text { balance training }\end{array}$ & 40 & 86 & 28 & 50 & 30 & 8 \\
\hline 2 & $\begin{array}{l}\text { Bilateral } \\
\text { vestibulopathy }\end{array}$ & $\begin{array}{l}\text { Specific organ therapy, } \\
\text { balance training, gait } \\
\text { training }\end{array}$ & 20 & 80 & 12 & 48 & 40 & 12 \\
\hline 3 & Normal & Virtual reality & 60 & 90 & 38 & 52 & 18 & 8 \\
\hline 4 & Ab utricular & $\begin{array}{l}\text { Specific organ therapy, } \\
\text { balance training }\end{array}$ & 50 & 86 & 38 & 46 & 22 & 10 \\
\hline 5 & Ab lateral canal & $\begin{array}{l}\text { Specific organ therapy, } \\
\text { balance training }\end{array}$ & 20 & 30 & 32 & 36 & 56 & 48 \\
\hline 6 & Normal & Virtual reality & 54 & 88 & 38 & 48 & 22 & 10 \\
\hline 7 & Normal & Virtual reality & 58 & 90 & 40 & 50 & 20 & 8 \\
\hline 8 & Ab lateral canal & $\begin{array}{l}\text { Specific organ therapy, } \\
\text { balance training }\end{array}$ & 60 & 96 & 40 & 52 & 18 & 8 \\
\hline 9 & Ab utricular & $\begin{array}{l}\text { Specific organ therapy, } \\
\text { balance training }\end{array}$ & 62 & 92 & 38 & 50 & 24 & 10 \\
\hline 10 & Ab utricular & $\begin{array}{l}\text { Specific organ therapy, } \\
\text { balance training }\end{array}$ & 30 & 90 & 38 & 56 & 30 & 12 \\
\hline 11 & Normal & Virtual reality & 58 & 94 & 40 & 52 & 24 & 10 \\
\hline 12 & Normal & Virtual reality & 54 & 92 & 39 & 50 & 22 & 8 \\
\hline 13 & Ab lateral canal & $\begin{array}{l}\text { Specific organ therapy, } \\
\text { balance training }\end{array}$ & 40 & 90 & 28 & 54 & 28 & 8 \\
\hline 14 & Ab utricular & $\begin{array}{l}\text { Specific organ therapy, } \\
\text { balance training }\end{array}$ & 50 & 90 & 36 & 52 & 20 & 10 \\
\hline 15 & Normal & Virtual reality & 70 & 94 & 48 & 54 & 22 & 8 \\
\hline 16 & Normal & Virtual reality & 36 & 86 & 36 & 50 & 18 & 10 \\
\hline 17 & Ab lateral canal & $\begin{array}{l}\text { Specific organ therapy, } \\
\text { balance training }\end{array}$ & 50 & 96 & 40 & 54 & 24 & 12 \\
\hline 18 & Ab lateral canal & $\begin{array}{l}\text { Specific organ therapy, } \\
\text { balance training }\end{array}$ & 56 & 88 & 36 & 50 & 22 & 8 \\
\hline 19 & Normal & Virtual reality & 60 & 92 & 42 & 54 & 16 & 8 \\
\hline 20 & Ab lateral canal & $\begin{array}{l}\text { Specific organ therapy, } \\
\text { balance training }\end{array}$ & 54 & 86 & 34 & 50 & 24 & 10 \\
\hline 21 & $\begin{array}{l}\text { Ab lateral and } \\
\text { posterior canal }\end{array}$ & $\begin{array}{l}\text { Specific organ therapy, } \\
\text { balance training }\end{array}$ & 48 & 84 & 34 & 48 & 28 & 14 \\
\hline 22 & $\begin{array}{l}\text { Ab lat, ant and } \\
\text { post, saccule }\end{array}$ & Ab lat, ant and post, saccule & 40 & 60 & 32 & 46 & 34 & 16 \\
\hline 23 & Normal & Virtual reality & 60 & 88 & 38 & 56 & 18 & 10 \\
\hline 24 & Normal & Virtual reality & 64 & 90 & 40 & 56 & 16 & 8 \\
\hline 25 & Ab lateral canal & $\begin{array}{l}\text { Specific organ therapy, } \\
\text { balance training }\end{array}$ & 50 & 84 & 34 & 48 & 28 & 12 \\
\hline 26 & $\begin{array}{l}\text { Ab lateral and } \\
\text { posterior canal }\end{array}$ & $\begin{array}{l}\text { Specific organ therapy, } \\
\text { balance training }\end{array}$ & 46 & 82 & 32 & 48 & 36 & 12 \\
\hline 27 & Ab utricular & $\begin{array}{l}\text { Specific organ therapy, } \\
\text { balance training }\end{array}$ & 52 & 90 & 34 & 50 & 24 & 8 \\
\hline 28 & Ab lateral canal & $\begin{array}{l}\text { Specific organ therapy, } \\
\text { Balance training }\end{array}$ & 38 & 86 & 38 & 52 & 40 & 10 \\
\hline 29 & Ab lateral canal & $\begin{array}{l}\text { Specific organ therapy, } \\
\text { balance training }\end{array}$ & 44 & 88 & 34 & 50 & 36 & 12 \\
\hline
\end{tabular}




\begin{tabular}{|c|c|c|c|c|c|c|c|c|}
\hline Subjects & Vestibulometry & $\begin{array}{l}\text { Physical therapy } \\
\text { intervention }\end{array}$ & $\begin{array}{l}\text { Abc }(\%) \text { pre } \\
\text { treat }\end{array}$ & $\begin{array}{l}\text { Abc }(\%) \text { post } \\
\text { treat }\end{array}$ & $\begin{array}{l}\mathrm{Bbs}\left(\_/ 56\right) \\
\text { pre treat }\end{array}$ & $\begin{array}{l}\operatorname{Bbs}\left(\_/ 56\right) \\
\text { post treat }\end{array}$ & $\begin{array}{l}\text { Dhi pre } \\
\text { treat }\end{array}$ & $\begin{array}{l}\text { Dhi post } \\
\text { treat }\end{array}$ \\
\hline 30 & Ab lateral canal & $\begin{array}{l}\text { Specific organ therapy, } \\
\text { balance training }\end{array}$ & 46 & 90 & 32 & 50 & 40 & 16 \\
\hline 31 & Ab utricular & $\begin{array}{l}\text { Specific organ therapy, } \\
\text { balance training }\end{array}$ & 54 & 90 & 36 & 54 & 36 & 12 \\
\hline 32 & Normal & Virtual reality & 58 & 88 & 39 & 55 & 40 & 12 \\
\hline 33 & Normal & Virtual reality & 56 & 92 & 42 & 54 & 18 & 8 \\
\hline 34 & $\begin{array}{l}\text { Ab lateral and } \\
\text { posterior canal }\end{array}$ & $\begin{array}{l}\text { Specific organ therapy, } \\
\text { balance training }\end{array}$ & 48 & 89 & 32 & 52 & 24 & 6 \\
\hline 35 & Ab lateral canal & $\begin{array}{l}\text { Specific organ therapy, } \\
\text { balance training }\end{array}$ & 46 & 92 & 33 & 51 & 18 & 8 \\
\hline 36 & Normal & Virtual reality & 60 & 90 & 41 & 53 & 28 & 8 \\
\hline 37 & $\begin{array}{l}\mathrm{Ab} \text { lat, ant and } \\
\text { post, saccule }\end{array}$ & $\mathrm{Ab}$ lat, ant and post, saccule & 38 & 86 & 39 & 54 & 26 & 10 \\
\hline 38 & Ab lateral canal & $\begin{array}{l}\text { Specific organ therapy, } \\
\text { Balance training }\end{array}$ & 45 & 91 & 38 & 53 & 20 & 8 \\
\hline 39 & Normal & Virtual reality & 42 & 96 & 45 & 54 & 14 & 6 \\
\hline 40 & Normal & Virtual reality & 52 & 88 & 42 & 52 & 28 & 8 \\
\hline 41 & Ab lateral canal & $\begin{array}{l}\text { Specific organ therapy, } \\
\text { Balance training }\end{array}$ & 38 & 78 & 30 & 46 & 44 & 16 \\
\hline 42 & Normal & Virtual reality & 50 & 90 & 40 & 54 & 28 & 8 \\
\hline 43 & Normal & Virtual reality & 48 & 89 & 40 & 55 & 26 & 10 \\
\hline 44 & $\begin{array}{l}\text { Ab lat, ant and } \\
\text { post, saccule }\end{array}$ & $\begin{array}{l}\text { Specific organ therapy, } \\
\text { balance training }\end{array}$ & 45 & 88 & 38 & 52 & 24 & 12 \\
\hline 45 & $\mathrm{Ab}$ utricular & $\begin{array}{l}\text { Specific organ therapy, } \\
\text { balance training }\end{array}$ & 46 & 90 & 39 & 52 & 28 & 10 \\
\hline 46 & Ab lateral canal & $\begin{array}{l}\text { Specific organ therapy, } \\
\text { balance training }\end{array}$ & 52 & 91 & 40 & 51 & 26 & 8 \\
\hline 47 & Normal & Virtual reality & 44 & 88 & 42 & 54 & 22 & 6 \\
\hline 48 & Ab lateral canal & $\begin{array}{l}\text { Specific organ therapy, } \\
\text { balance training }\end{array}$ & 46 & 90 & 40 & 54 & 24 & 8 \\
\hline 49 & Normal & Virtual reality & 52 & 90 & 44 & 56 & 20 & 6 \\
\hline 50 & Ab utricular & $\begin{array}{l}\text { Specific organ therapy, } \\
\text { balance training }\end{array}$ & 50 & 92 & 43 & 55 & 30 & 8 \\
\hline 51 & Ab utricular & $\begin{array}{l}\text { Specific organ therapy, } \\
\text { balance training }\end{array}$ & 62 & 94 & 45 & 54 & 22 & 6 \\
\hline 52 & Normal & Virtual reality & 34 & 96 & 48 & 56 & 18 & 4 \\
\hline 53 & Normal & Virtual reality & 42 & 95 & 46 & 56 & 16 & 6 \\
\hline
\end{tabular}

\section{Discussion}

Physical therapy is basically of two forms viz:

Non-specific physical therapy To improve the general balance function and also expedite the process of vestibular compensation. As these are generalised, non-specific exercises, they are not targeted to improve the function of any particular balance organ that has been damaged by disease. This are

(a) Cawthrone-Cooksey exercises.

(b) Yogic asanas.

(c) Tai Chi exercises.
Of these three, though the Cawthrone-Cooksey exercises are more widely practised and have stood the test of time, yet the other modalities of non-specific balance improving exercise i.e., Yogic asanas and Taichi have been found to be more efficacious. These exercises, including the Cawthrone-Cooksey exercises need to be taught and demonstrated by trained and qualified physical therapists and experts in yoga and tai chi (Fig. 9). The common practice of doctors giving some tear-away sheets of the CawthroneCooksey exercises to patients (circulated by some pharmaceutical companies with the names of some anti-vertigo products advertised therein) is farcical and defeats, if not makes a joke of the purpose of these exercises. These 


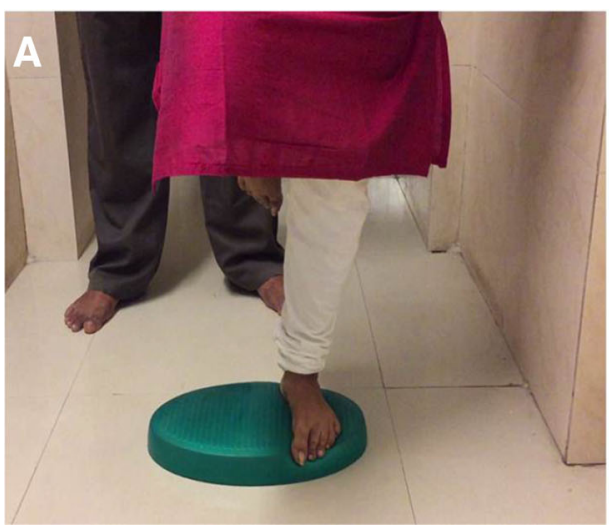

Fig. 5 a, b Exercises that augment the balance faculty. The patient is made to stand on especially made foam pads of varying firmness commercially available called balance trainers (front Theraband). The exercises start initially on firm pads and then on pads of increasing softness so that the proprioceptive input is gradually deceased step by step to vary the proprioceptive input in a graded fashion. The

exercises are beneficial only if properly done and for this focussed first hand training from trained experts who understand the physiology of balance and can interpret vestibulometric findings is mandatory.

Now modern technology like virtual reality [10] is also being used to restore stability in balance disorder patients and is instrumental in improving the plight of balance challenged patients in a big way. Virtual reality programs especially made for balance disorder patients entails presenting to the patient's senses a computer generated virtual environment that isn't really there, but from the patient's perspective is perceived as real. Through virtual reality the patient can be exposed to different situations that simulate conditions where a normal person is expected to experience somewhat frightening unsteadiness e.g., standing at the edge of a precipice or a cliff of a mountain and the vestibular system can be exposed to very challenging situations. These exercises are very effective in allaying the feel of insecurity and the crippling fear of fall that a lot of balance disorder patients often experience. Correcting the mental fear and anxiety/insecurity induced by these situations is a very important part of therapy. Moreover such challenging (virtual) exposures train the brain to evolve the right strategies for maintenance of balance in difficult and demanding situations. Many, if not most patients who have balance disorders develop a severe sense of insecurity, lack of self-confidence and mental anxiety that compounds the balance problem. The mental insecurity (e.g., fear of falls) and the unsteadiness perpetuate each other and the patient goes downhill and ultimately becomes a psychological wreck with severe agoraphobia. This needs effective management without which treatment is never successful. An unpublished ongoing study being carried out by the first author shows that virtual reality therapy is far more

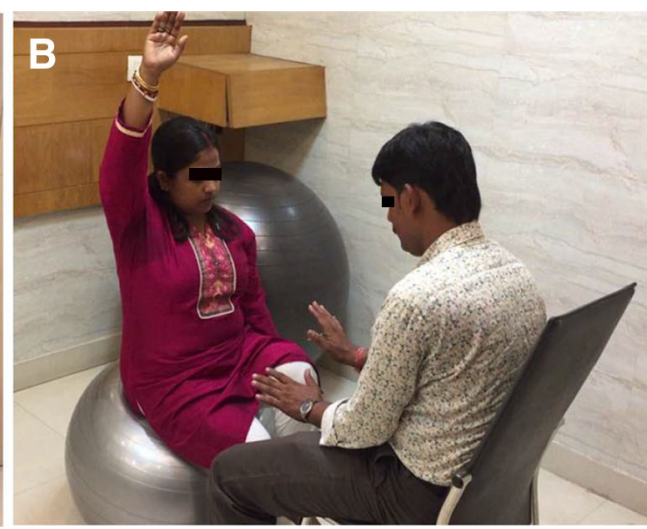

exercises on each pad starts with the patient first standing on both legs with eyes open then with eyes closed then on one leg etc. such that the exercises become gradually more challenging in every step. Balance enhancing exercises using the gym ball available from fitness equipment stores

effective than SSRIs and counselling in these patients where there is a psychic overlay compounding the balance problem and in patients of psychic balance disorders like Phobic Postural Vertigo (PPV) and Persistent Perceptive Postural Dizziness (PPPD) [11]. Though there are some published studies comparing vestibular physiotherapy like the Cawthrone exercises with VR therapy in patients of vestibulopathies, these studies do not bring out the true efficacy of VR therapy as VR is not the best modality for patients with vestibulopathy [12]. For patients who have purely a vestibular damage without any psychic involvement, physical therapy is the best choice. VR therapy is best suited specifically for balance disorder patients with a psychic overlay and fear of falls as in psychogenic vertigo. In such patients the efficacy of VR therapy is very high.

Specific organ-targeted physical therapy Modern research has unravelled many of the mysteries of the functioning of the balance system and has advanced our understanding of the mechanism of balance enormously. We now know the exact function of each part of the balance system. The balance organs in the ear have different and very specific and specialised sensors for identifying different types of body movement. Today we know that the saccule senses up-down movement in the vertical axis, the utricle senses linear movement in the horizontal axis i.e., side to side and front-back movement and the three semi-circular canals sense angular movement in three different planes [19]. In diseases of the balance system, one or more of these sensors are often damaged. With the development of our understanding of the finer aspects of the mechanism of balance, the science of vestibulometry i.e., medical investigations to evaluate the functional and structural integrity of the balance system when afflicted by disease has also been vastly 

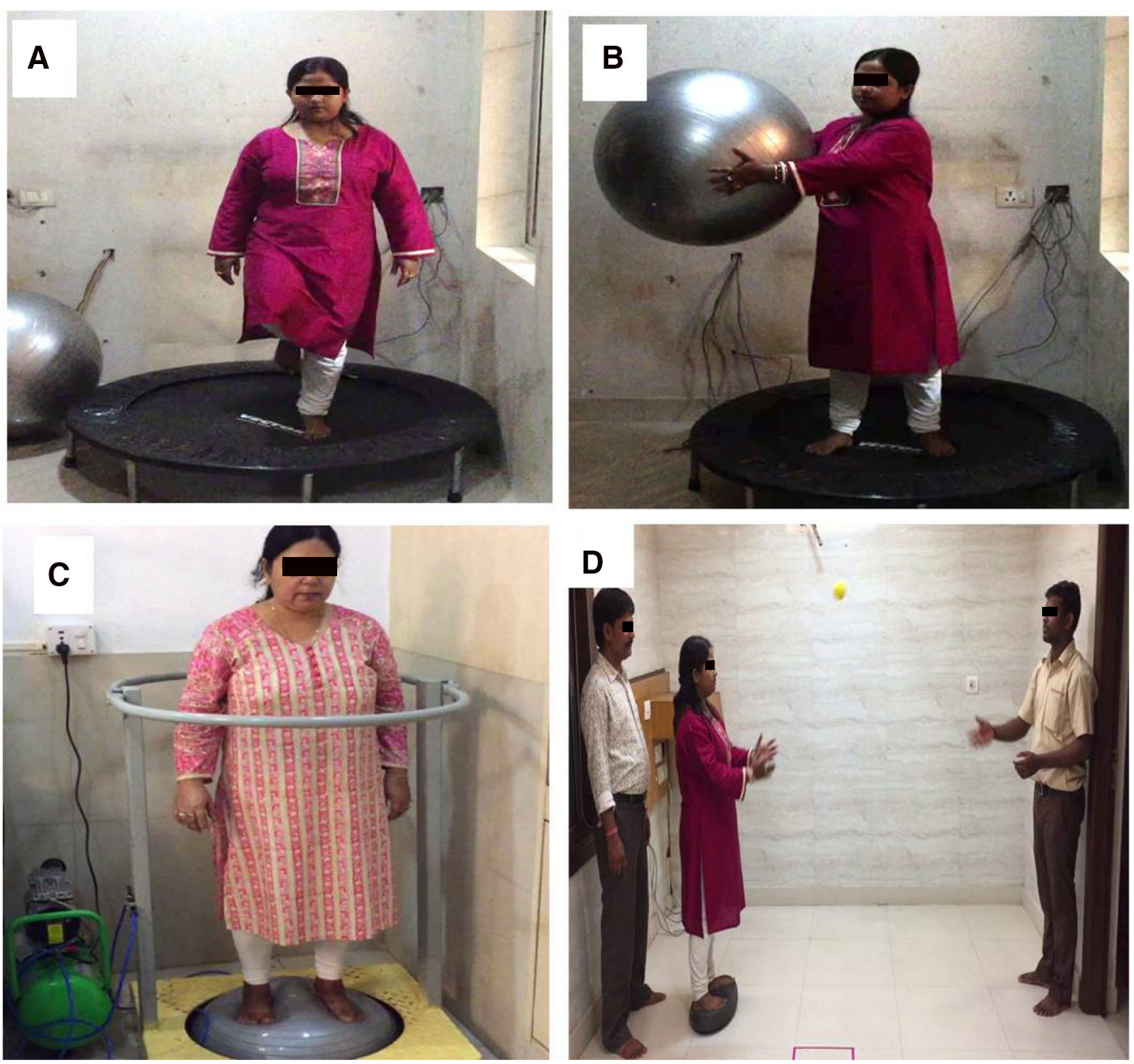

Fig. 6 a, b Other exercises to boost the patient's balance capabilities. In Fig. 3a, b the patient is standing on a trampoline first on two legs then on one leg and is given tasks like holding a ball and swinging it from side to side. In Fig. $6 \mathrm{c}$ the patient is asked to stand on an inflatable Bosuball available in fitness equipment stores. The Bosuball is connected to an electrical air-pump such that the contour of and softness of the ball can be changed by operating the air-pump and the

task of maintaining balance can be made more and more difficult. Many such easily available instruments can be improvised into very effective gadgets for physical therapy of patients with balance disorders. Figure 6d: the patient standing on a foam pad is made to perform tasks like catching a ball. All these exercises enhance the balance powers of the patient

refined. Advancements in diagnostic neurotology have sharpened the diagnostic techniques [13] to such an extent that the modern vestibular function tests like videonystagmography (VNG), cervical and ocular VEMP [14, 19] subjective visual vertical tests (SVV) [15, 19], video head impulse test (VHIT) [16, 19] the dynamic visual acuity test (DVA) [17, 19]., etc (Fig. 10). can accurately and very precisely identify the exact part or function of the balance system that has been damaged and specify which type of body movement is not being adequately sensed by the diseased balance organs or which particular mechanism is at fault. That specific part of the balance organ can then be very precisely stimulated by physical therapy.

Vestibulometry [19] today can so very precisely localise and quantify the dysfunction in the defective organ that a modern neurotologist using the advanced vestibulometric tests $[18,19]$ available today can specify that the saccule of one side is $56.2 \%$ defective or that the posterior semicircular canal of one side is $39.62 \%$ defective or that there is a in a specific defect in the oculomotor function like that the latency of saccadic eye movement is increased. In keeping with the advancements in diagnostic neurotology, therapeutic neurotology especially physical therapy has also undergone great sophistication. Specific physical therapy to stimulate the functional status of the defective sense-organ is now possible. If the cVEMP identifies that 


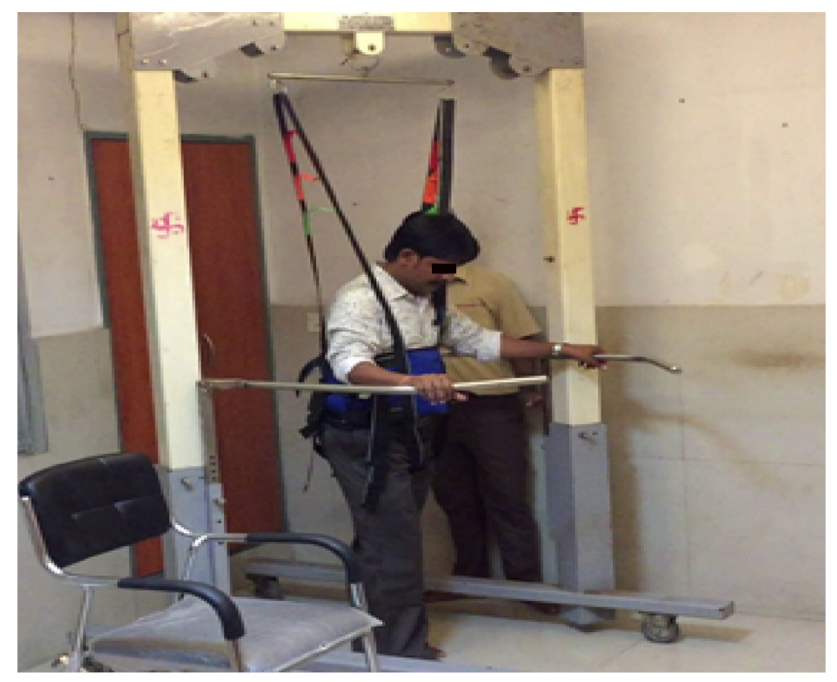

Fig. 7 Set up for therapy for patients of gait disorders like gait apraxia, cerebellar ataxia and patients with paraplegia

the saccule is partly damaged, it would imply that up-down movements are not being adequately sensed; physical therapy to stimulate the saccule by repeatedly exposing the patient to movement in the vertical axis is then instituted. If the anterior semi-circular canal of the right side is found to be malfunctioning then angular stimulation of the head in the plane of the right anterior semi-circular canal is initiated and so on. A huge lot of electro-mechanical gadgetry is now available for this some of which has been developed by the author. We can now specifically and individually stimulate the utricle, the saccule and/or one or more of the three semi-circular canals by organ targeted physical therapy. The results of such physical therapy are extremely promising. Just as physicians diagnose an infection, then do a culture sensitivity to identify the offending infective agent and then prescribe antibiotics to eradicate the infection, in modern neurotology to the same road-map is followed. The neurotologist today diagnoses the exact site of lesion, unambiguously identifies the defective sense organ and the extent and nature of lesion and prescribes specific physical therapy to enhance the functionality of the defective organ that has been identified by vestibulometry along with specific medication targeted to treat the underlying causative disease as and when required. Just as non-specific medical therapy with anti-vertigo drugs is now a thing of the past denounced by modern neurotologists, similarly non-specific physical exercises to improve general balance function is being supplemented with rather than replaced by specific therapy targeted to stimulate the dysfunctional sense organ/system in the vestibular system.

Experts in physical therapy for balance disorder patients and specialists in neuro rehabilitation work in coordination with neurotologists to provide a much better quality of life to most if not all balance disorder patients. This form of physical therapy is very scientific and logical and stimulates the residual function of any dysfunctional sense-organ in the vestibular system. Advancements in physical therapy

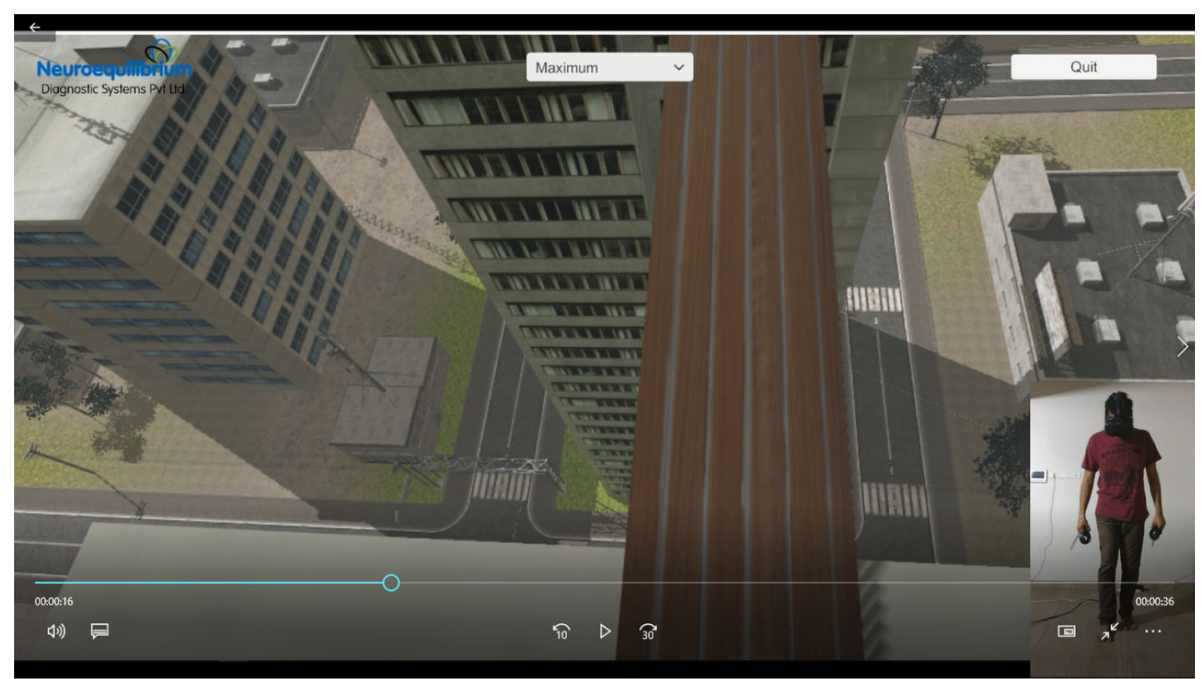

Fig. 8 Screen shot from a virtual reality (VR) program specifically developed through NeuroEquilibrium Diagnostic Systems under instructions of the author. Many such are also available from different internet sites. The patient wearing the VR goggles is shown in the inset and the visual surroundings all around as experienced by the patient in all dimensions not merely 3D is shown twodimensionally in the picture. The patient actually gets the multidimensional visual effect. The patient is exposed to a virtual situation whereby the patient gets the feeling of walking on a wooden plank without railings or any support. If the patient looks down on the sides he gets the visual feeling of the ground hundreds of feet below. The width of the plank can be changed from broad to narrow and very narrow and the height of the plank from the ground can be increased in instalments gradually making the task more difficult for the patient. The patient may also be made to get the feeling of standing on the edge of a roof without railings 


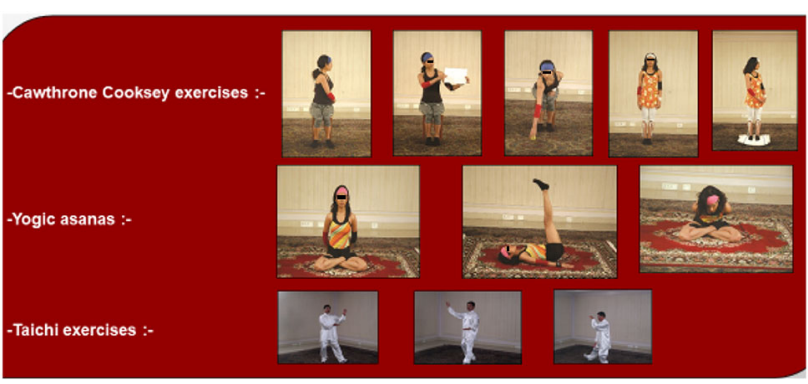

Fig. 9 Different exercises for vestibular rehabilitation

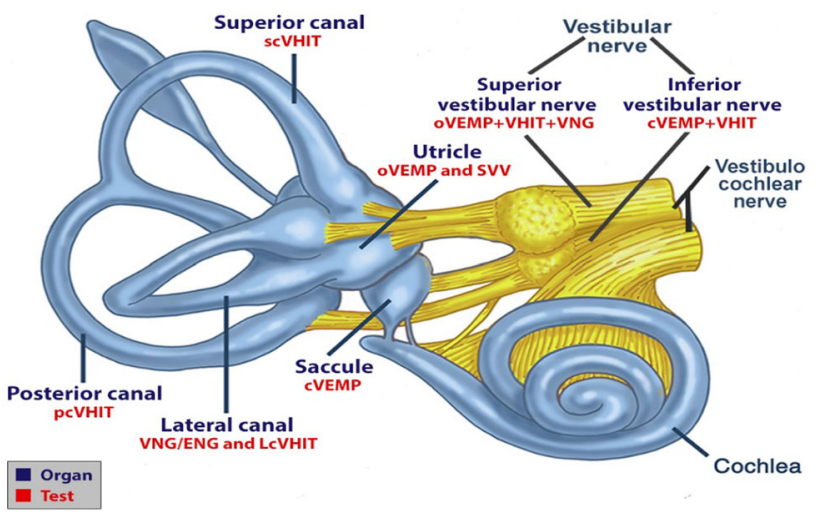

Fig. 10 Tests to assess each part of the vestibular labyrinth. Modern vestibulometry enables us to evaluate the functional status of each part of the vestibular labyrinth. Videonystagmography (VNG) assesses the function of the lateral semi-circular canal at low frequencies of vestibular stimulation, the Video Head Impulse Test (VHIT) assesses the functional status of the three semi-circular canals on both sides, the Vestibular Evoked Myogenic Potential Tests (VEMP) assess the function of the otolith organs-ocular VEMP assesses the utricular function and cervical VEMP assesses saccular function. The subjective visual vertical test (SVV) assesses the perception of the visual vertical which is believed to be a utricular function

have been able to enhance the quality of life of balance disorder patients tremendously. This is a small study involving the first 53 patients who enrolled in the specialised balance and gait disorders physiotherapy unit of Vertigo and Deafness Clinic in Kolkata, India over a period of 3 months. Further studies will be undertaken to evaluate and establish the efficacy of this new form of specific organ targeted physiotherapy.

\section{Conclusion}

Advancements in our understanding of vestibular physiology and how the physiology changes in different disease conditions and the recent developments in vestibulometry has induced a sea change in the management of balance disorders. Precise diagnosis of the exact site of lesion in the balance system as well as the nature of pathology is possible in most if not all patients of vertigo/imbalance today. Using the modern vestibulometric modalities today's neurotologists can accurately pin point whether there is a defect in the utricle or in the saccule or in any of the three semi-circular canals or in other parts/mechanisms of the balance system. In many cases by modern vestibulometry neurotologists can even diagnose whether a specific organ is malfunctioning at a high frequency of vestibular stimulation or at low frequencies of vestibular stimulation. Once the defective sense organ in the balance system is identified by the modern vestibulometric tests, the patient can be subjected to very specialised organ targeted vestibular physiotherapy using different modalities of physical therapy that is targeted specifically to the defective vestibular sense organ with very good outcomes. The current study evaluates the effect of specific organ targeted vestibular physical therapy using electromechanical devices devised by the first author and carried out by the second author. The results as evaluated by different parameters like the Activity Balance Confidence Scale, Burg Balance Scale and the Dizziness Handicap Inventory scale have shown remarkable improvement.

\section{References}

1. Obermann $\mathrm{M}$ et al (2014) Current treatment options in vestibular migraine. Front Neurol 5:257

2. Telian SA, Shepard NT (1996) Update on vestibular rehabilitation therapy. Otolaryngol Clin N Am 29:359-371

3. Thompson TL et al (2009) Vertigo: a review of common peripheral and central vestibular disorders. Ochsner J 9(1):20-26

4. Soto E et al (2010) Neuropharmacology of vestibular system disorders. Curr Neuropharmacol 8(1):26-40

5. Lacour $\mathrm{M}$ et al (2014) Interaction between vestibular compensation mechanisms and vestibular rehabilitation therapy: 10 recommendations for optimal functional recovery. Front Neurol $5: 285$

6. Rascol O, Hain TC, Brefel C et al (1995) Antivertigo medications and drug-induced vertigo. Drugs 50:777-791

7. Alsalaheen BA et al (2010) Vestibular rehabilitation for dizziness and balance disorders after concussion. J Neurol Phys Ther 34(20):87-93

8. Telian SA, Shepard NT (1996) Update on vestibular rehabilitation therapy. Otolaryngol Clin N Am 29:359-371

9. Han BI et al (2011) Vestibular rehabilitation therapy: review of indications, mechanisms, and key exercises. J Clin Neurol 7(4):184-196

10. Alahmari KA et al (2014) Comparison of virtual reality based therapy with customized vestibular physical therapy for the treatment of vestibular disorders. Neural Syst Rehabil Eng 22(2):389-399

11. Staab JP, Eckhardt-Henn A, Horii A, Jacob R, Strupp M (2014) Progress report of the behavioral subcommittee of the committee on classification of the Bárány Society. J Vestib Res 24:93-94

12. Gonçalves R et al (2012) Efficacy of virtual reality exposure therapy in the treatment of PTSD: a systematic review. PLoS One 7(12):e48469 
13. Wuyts FL, Furman J, Vanspauwen R, Van de Heyning P (2007) Vestibular function testing. Curr Opin Neurol 20(1):19-24

14. Akkuzu G, Akkuzu B, Ozluoglu LN (2006) Vestibular evoked myogenic potentials in benign paroxysmal positional vertigo and Meniere's disease. Eur Arch Otorhinolaryngol 263(6):510-517

15. Chetana $\mathrm{N}$ et al (2015) Subjective visual vertical in various vestibular disorders by using a simple bucket test. Indian J Otolaryngol Head Neck Surg 67(2):180-184

16. Miłoński J et al (2014) The use of videonystagmography head impulse test (VHIT) in the diagnostics of semicircular canal injuries in patients with vertigo. Int J Occup Med Environ Health 27(4):583-590

17. Peters BT et al (2012) Dynamic visual acuity testing for screening patients with vestibular impairments. J Vestib Res 22(2):145-151

18. McCaslin DL et al (2011) The influence of unilateral saccular impairment on functional balance performance and self-report dizziness. J Am Acad Audiol 22:542-549

19. Biswas A (2017) Clinical Audiovestibulometry. 5th edn. BhalaniPublishing House, Mumbai, India

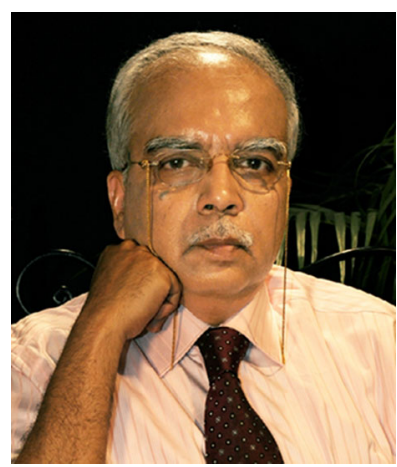

Anirban Biswas Practices in neurotology in Kolkata and is well known for his contribution in the development and popularisation of medical audiology and neurotology in India and abroad. Books authored by him are very popular among ENT specialists, neurologists and medical specialists who treat patients of vertigo and deafness. Some of his achievements are listed following: Past-President of the Association of Otolaryngologists of India (2010-2011).
Past-president of the Neurotological and Equilibriometric Society of India (1999-2001). Ex-editor of the Indian Journal of Otolaryngology and Head and Neck Surgery (2000-2005). Selected as member of Barany society for his contribution to the discipline of neurotology in 1997. This is the highest international academic recognition in neurotology. President Indian Academy of Otolaryngology Head and Neck Surgery (2016-2017). Vice-President International Neurotological and Equilibriometric Society (2016-2017). Recipient of TatoClaussen award for extraordinary achievements in the field of applied neurotology and therapies of neurotological disorders-presented by the International Neurotological and Equilibriometric Society on 16th April 2010 in Its 37th annual scientific conference held at Bad Kissingen, Germany. Authored two university approved text cum reference books on neurotology viz, Clinical Audiovestibulometry which is now in its 5th edition and is popular internationally and An introduction to neurotology now in the 2nd edition. Other books authored are (1) Physical therapy for balance disorder patients, (2) A holistic approach to balance disorders and its ethical management (3) Understanding hearing aids and (4) Contemporary hearing aids and related devices. Authored many patient education booklets, books and educational CDs for doctors, articles in several national and international journals. Conducts the prestigious neurotology workshop regularly every year in India which is a learning ground for upcoming neurotologists in India and the neighbouring countries and is now the most popular neurotology course in this part of the world. Previously used to conduct an yearly workshop on Vertigo at London Whipp's Cross Hospital. Delivered guest lectures and conducted panel discussions in numerous ENT and Neurotology conferences in India and abroad. Runs a very sophisticated neurotology clinic in Kolkata VERTIGO and DEAFNESS CLINIC (www.vertigoclinic.in) which is equipped with all modern diagnostic and therapeutic gadgetry for diagnosis and treatment of patients suffering from hearing and balance disorders. 